УДК 621.9.06-119

Матвиенко В. А. ${ }^{1}$, Двейрин А. 3. ${ }^{2}$, Василевский Е. Т. ${ }^{2}$, Романович Г. Н. ${ }^{2}$, Рудъко А. Н.

${ }^{1}$ АО «Украинский научно-исследовательский институт авиационной технологии». Украина, г. Киев

${ }^{2}$ Государственное предприятие «АНТОНОВ». Украина, г. Киев

\title{
КРЕПЕЖНЫЕ СИСТЕМЫ ДЛЯ СБОРКИ СОВРЕМЕННЫХ САМОЛЕТОВ
}

Кратко представлены результаты анализа мирового рынка крепежных систем для авиационных конструкций, приведены основные производители, выделены основные тенденции развития рынка. Выполнен анализ существующего нормативного базиса крепежных систем, используемого авиастроительными предприятиями Украины. Предложены альтернативные варианты крепежных систем, описаны основные этапы их апробации, а также представлены отдельные результаты выполнения таких работ. [dx.doi.org/10.29010/081.9]

Ключевые слова: соединение; крепежные системы; заклепки высокого сопротивления срезу; Ergo-Tесh; апробащия.

Описание вопроса

Общепризнано, что трудоемкость сборки составляет 45...55\% общей трудоемкости самолета, в том числе, трудоемкость выполнения соединений порядка $30 \%[1 ; 2]$

В конструкции планера современного транспортного (пассажирского) самолета, в зависимости от его габаритов, используется от 0,5 до 2,5 млн. единиц крепежных изделий [2; 3].

Мировой опыт показывает, что, несмотря на то, что стоимость крепежа составляет всего 3\% стоимости самолета, нерешенность проблем в сфере крепежа приводит к серьезным сбоям в серийном производстве. Только компания Boeing и её более 500 субпоставщиков потребляют более 700 млн. единиц крепежа в год. Так, например, одной из причин задержки поставки самолетов Boeing 787 в 2007-2009 гг. [4] и самолетов Airbus A380 [5] был мировой дефицит авиационного крепежа (более 100 млн. единиц), используемого для сборки планера. Средняя рыночная стоимость единицы современного крепежа ведущих мировых производителей составляет $\approx 8,0$ долл.США.

В результате проведенной в течение нескольких лет консолидации в сфере производства авиационного крепежа, на мировом рынке доминируют три ведущих производителя, которые обеспечивают порядка 80\% потребляемого крепежа: Alcoa Fastening System \& Rings (AFSR), Precision Castparts Corp. (PCC), Lisi Aerospace. Безусловным лидером по объему продаж является AFSR, в состав которой входят ряд компаний: Huck, Fairchild, Kaynar, Republic Fasteners и др. [6].
Наряду с процессами консолидации производителей крепежа совершенствуется и трансформируется схема его поставок потребителям. Комплекс этих мер призван точно в срок и в нужном объеме обеспечить крепежом заводы финальной сборки и их поставщиков 1-2 уровней кооперации, с учетом стремительного роста темпа производства самолетов. Так, по данным [7] цикл окончательной сборки самолета Boeing737 составляет около 30 дней, а самолета Boeing-787 - 3 дня. Если ранее объем работ, выполняемых кооперантами ведущих мировых производителей самолетов, составлял 35-50\% общей трудоемкости производства самолета, то в настоящее время этот показатель для поставщиков Boeing, Airbus, Bombardier составляет около 70\%. В соответствии с данной тенденцией меняется и соотношение потребляемого крепежа заводами финальной сборки и компаниями-кооперантами (рис. 1).

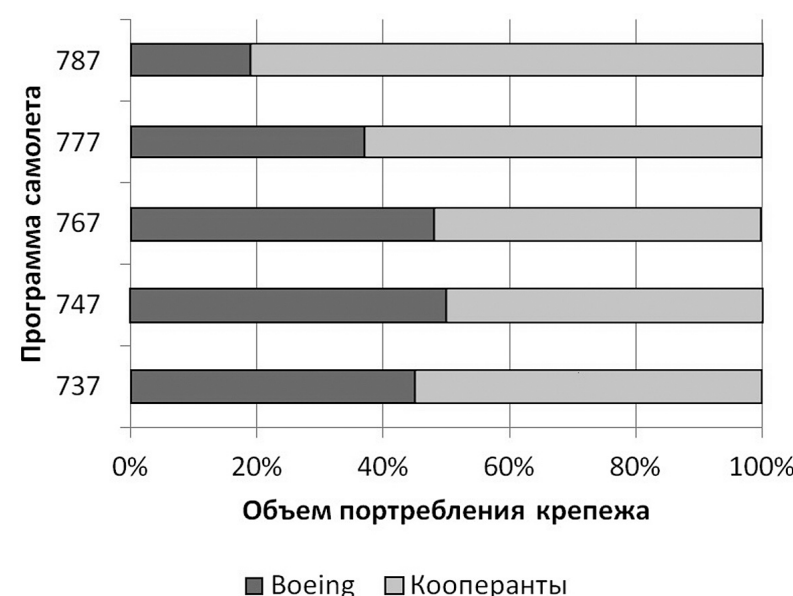

Рис. 1. Соотношение объемов потребления крепежа компанией Boeing и её кооперантами [3] 
Современная, трансформированная модель обеспечения потребностей авиастроительных компаний крепежом характеризуется следующими основными особенностями:

- централизованное размещение заказов на поставку крепежа для производителей самолетов и их кооперантов;

- поставка крепежа от определенных производителей на основании долгосрочных контрактов;

- возможность производителей крепежа постоянного мониторинга планов производства и текущего объема запасов крепежа у производителей самолетов.

Современные крепежные системы, используемые ведущими мировыми производителями транспортных и пассажирских самолетов, включают порядка 15 типов крепежа (заклепки, болты, болтзаклепки, Hi-lok и другие), изготавливаемых как в соответствии с национальными авиационными стандартами (NAS), так и корпоративными. При этом, следует отметить, что одной из очевидных тенденций является переориентация на корпоративные стандарты, регламентирующие более жесткие требования, в частности, к поставщикам крепежа и его качеству. В настоящее время 80-90\% крепежа, используемого в самолетах Boeing, изготавливается по стандартам Boeing Aircraft Company specifications (BAC).

Boeing и его шесть основных поставщиков-кооперантов первого уровня (Alenia Aeronautica, Spirit AeroSystems, Vought, Fuji Heavy Industries, Kawasaki Heavy Industries, Mitsubishi Heavy Industries) потребляют до 94-95\% общего количества крепежа, изготавливаемого по стандартам BAC. При этом, в целом, поставщиками других уровней для Boeing являются более 500 компаний.

Наиболее массово применяемыми системами в конструкции планера самолетов компаний Boeing и Airbus являются болт-заклепки и Hi-Lok. Так, количество крепежа HiLok составляет до 45\% общего количества крепежных единиц в конструкции самолетов Boeing разных модификаций.

В целом, конструктивное совершенствование современных крепежных систем ведущих мировых производителей направлено на достижение следующих основных целей:

- повышение весовой эффективности сборных частей планера;

- повышение уровня эксплуатационных нагрузок, воспринимаемых конструкцией планера в зоне соединений;

- обеспечение топливной и воздушной герметичности конструкций в зоне соединений без применения дополнительных средств герметизации;

- возможность использования в условиях автоматического выполнения соединений;

- обеспечение комплекса специфических требований к крепежным системам, используемым для сборки конструкций из полимерных композиционных материалов (ПКМ).

К специфическим конструктивным требованиям, предъявляемым к крепежным системам для сборки конструкций из ПКМ, следует отнести следующее:

- гальваническая совместимость крепежных систем и материала соединяемых элементов конструкции;

- снижение уровня технологических усилий, необходимых для выполнения соединения для обеспечения неповреждаемости собираемой конструкции;

- эффективное рассеяние в результате возможного попадания удара молнии в крепежный элемент, расположенный в конструкции топливных отсеков планера самолета.

На рис. 2, в качестве примеров, представлена информация, иллюстрирующая современные технические решения, отвечающие перечисленным

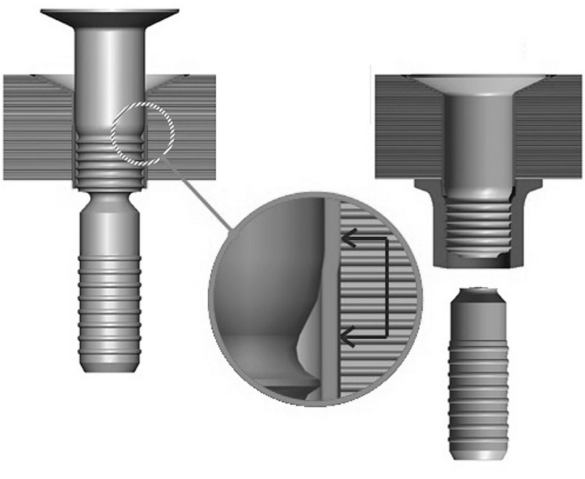

$\mathrm{a}$

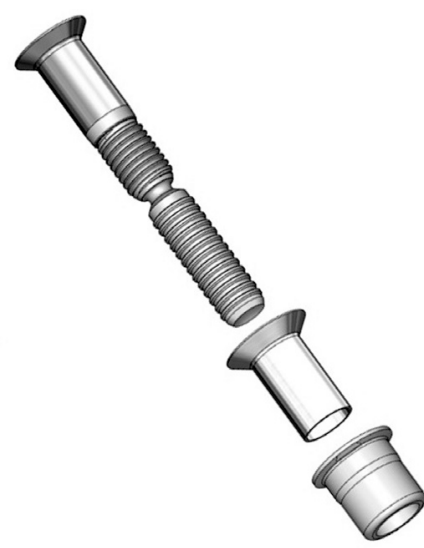

б

Рис. 2. Болт-заклепки компании AFSR для выполнения соединений в топливных отсеках из ПКМ для обеспечения молниезащиты: а - технология постановки; б - конструкция крепежа 


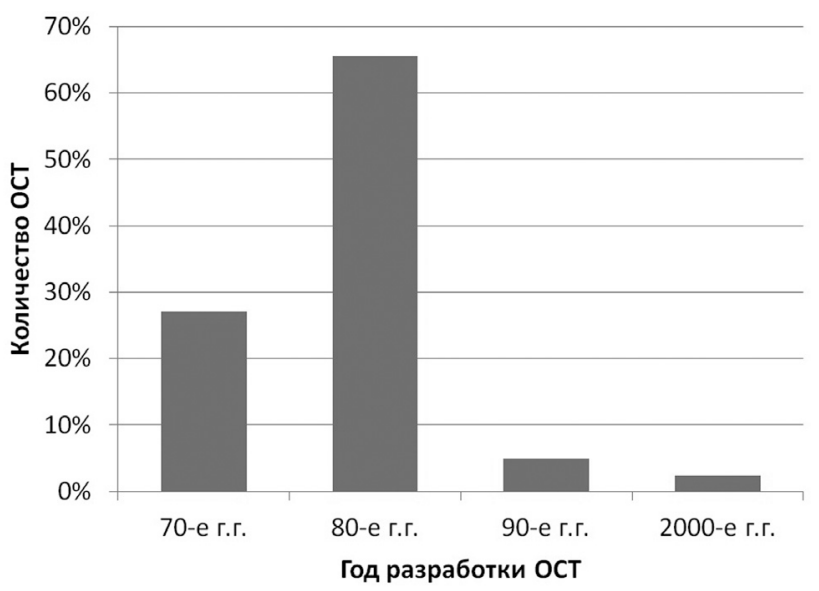

Рис. 3. Структура массива ОСТ на крепеж по годам разработки

выше требованиям, и предлагаемые одним из мировых лидеров в сфере разработки и производства крепежных систем для авиационных конструкций - компанией AFSR.

Оптимизация конструктивно-технологических параметров и системы поставок для серийного производства крепежных систем, используемых в конструкции транспортных и пассажирских самолетов семейства «АНТОНОВ» нового поколения, является в настоящее время одним из приоритетных направлений совместных научно-исследовательских и опытно-технологических работ ГП «АНТОНОВ» и Украинского научно-исследовательского института авиационной технологии (УкрНИИАТ).

Конструкция планера самолета семейства Ан148/158/178 содержит около 1,2 млн. крепежных единиц. Весь крепеж, используемый в настоящий момент времени в конструкции самолетов семейства «АНТОНОВ», изготавливается в соответствии с отраслевыми (авиационными) стандартами (ОСТ), разработанными, преимущественно, в 1970-1980 годах (рис. 3).

Порядка 60\% крепежных единиц представляют собой стержневые заклепки из алюминиевого сплава В65, изготавливаемые на оборудовании ГП «АНТОНОВ». Остальные 40\% общего количества крепежных единиц закупаются на стороне и представляют болты с гайками, болт-заклепки, крепеж односторонней постановки (заклепки с сердечником, заклепки высокого сопротивления срезу).

\section{Решение вопроса}

Результаты проведенного комплексного анализа возможных путей и моделей оптимизации конструктивно-технологических параметров крепежа и системы его поставок для серийного производства, свидетельствуют о следующем:
- оптимизация в части, касающейся стержневых заклепок, изготавливаемых ГП «АНТОНОВ», должна обеспечивать их стабильное качество, что позволит использовать автоматическое оборудование для клепки панелей, секций панелей, агрегатов планера самолета;

- с учетом мирового опыта, целесообразно оценить возможность использования для сборки конструкции современных и перспективных моделей самолетов «АН» крепежных систем, выпускаемых ведущими зарубежными компаниями.

Проведенный сравнительный анализ типов крепежных систем, используемых в конструкции планера самолетов «АНТОНОВ» и предлагаемых на мировом рынке, позволил сформировать перечень альтернативных типов крепежных систем, конструктивно-технологическая и прочностная оценка которых проводится в рамках первого этапа совместных работ ГП «АНТОНОВ» и УкрНИИАТ с участием компании AFSR (рис. 4).

Оценка возможности применения альтернативных крепежных систем предусматривает выполнение комплекса работ, включающих отработку технологии выполнения соединений, проведение сравнительных прочностных испытаний образцов соединений, разработку корпоративных нормативных документов по применению альтернативных крепежных систем.

В рамках первого этапа работы была выполнена апробация технологии постановки заклепок высокого сопротивления срезу Ergo-Tech, а также проведены усталостные испытания. Данный крепеж является двухкомпонентным и состоит из стальной втулки и титанового сердечника (рис. 5), установка выполняется с односторонним подходом. Простой метод установки исключает появления реактивного крутящего момента, воздействующего на работника или робота, а также не требует дополнительной операции - зачистки. Дополнительные преимущества такого крепежа по сравнению с болтами: более низкая стоимость установки крепежа; меньшая масса установленного крепежа. Такой крепеж может применяться для конструкций из металлических и композиционных материалов.

Особая форма канавок на технологическом хвостовике крепежа обеспечивает вхождение в зацепление шлицев на насадке инструмента и втулке крепежа, предотвращающих вращение втулки в процессе формообразования замыкающей головки.

Особенности крепежа Ergo-Tech:

- втулка выполнена из стали А-286 для лучшего формообразования замыкающей головки. Сердечник выполнен из титанового сплава $6 \mathrm{Al}-4 \mathrm{~V}$ для обеспечения минимального веса;

- крепеж устанавливается в отверстия, идентичные по диаметру, размерам зенкованного гнезда и толщинам пакета в соответствии с требованиями 


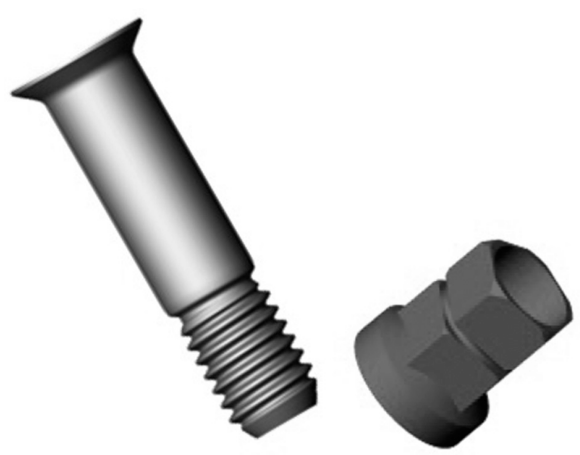

$\mathrm{a}$

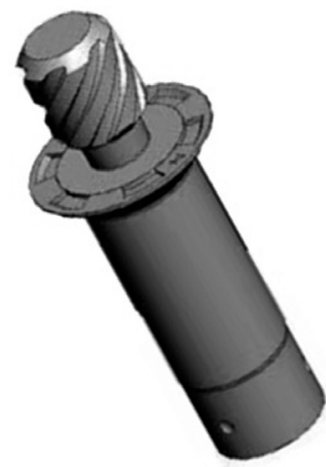

B

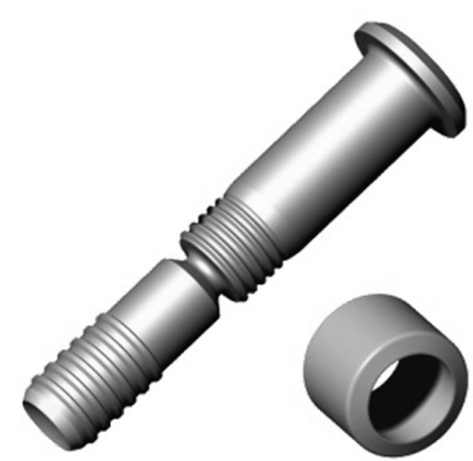

б

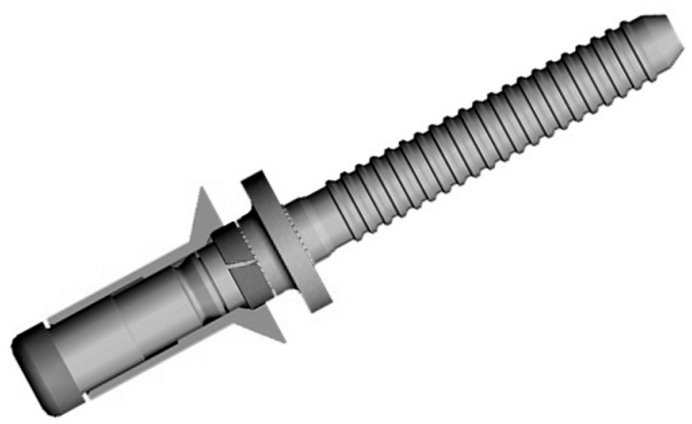

$\Gamma$

Рис. 4. Альтернативные типы крепежных систем для самолетов «АНТОНОВ»:

a) - стержень и гайка Veri-Light; б) - стержень и кольцо болт-заклепки LGPL;

в) - заклепка высокого сопротивления срезу Ergo-Tech; г) - заклепка с запирающимся сердечником типа UB100 и NAS1921
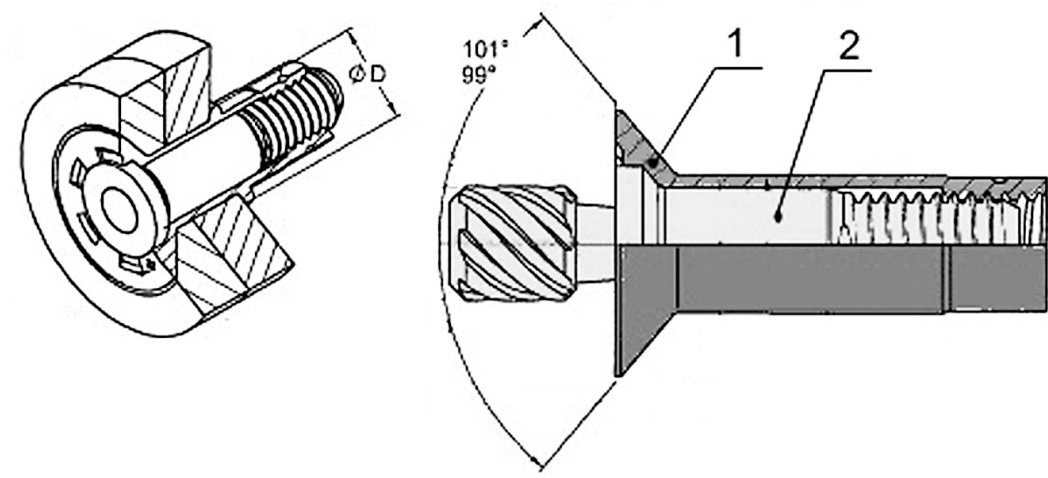

Рис. 5. Конструкция заклепок высокого сопротивления срезу ErgoTech: 1 - втулка; 2 - сердечник

для традиционных болтов. Доступен в исполнениях для работы на срез и на отрыв;

- шаг длин крепежа соответствует типовому для болтов значению 0,063” (1,6 мм) плюс 0,010” (0,25 мм) перекрытия;

- угол клиновидности пакета со стороны замыкающей головки до $5^{\circ}$;

- отрыв технологического хвостовика происходит заподлицо с торцом головки втулки при любых значениях толщины пакета;
- силы по формообразованию замыкающей головки воспринимаются втулкой, а не соединяемой конструкцией;

- высокое усилие сжатия пакета;

- высокая конструктивная прочность из-за цельной втулки и отсутствия резьбы в рабочей зоне;

- эргономичность (отсутствие шума и отдачи при отрыве технологического хвостовика);

- легкий эргономичный постановочный инструмент (рис. 6); 


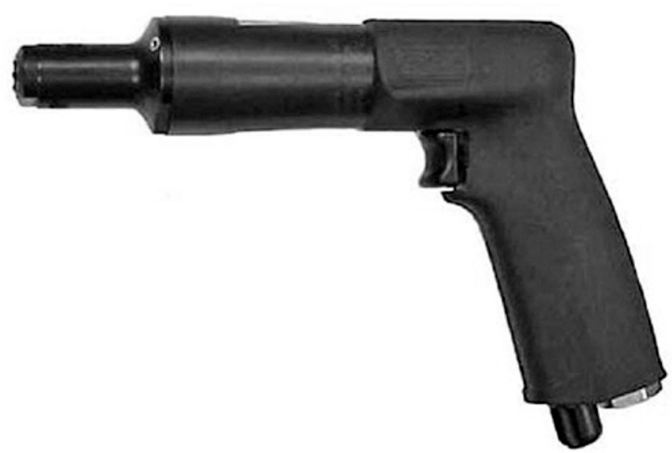

Рис. 6. Машина пневматическая модели ЕТТ-2000 для постановки крепежа Ergo Tech

- подходит для роботизированной установки.

Апробация технологии постановки заклепок высокого сопротивления срезу Ergo-Tech предусматривала выполнение следующих операций:
- сверление предварительных отверстий;

- обработка окончательных отверстий методом развертывания;

- зенкование гнезд под закладную головку;

- установка в отверстие и образование замыкающего элемента Ergo-Tech (рис. 7).

Под образованием замыкающего элемента Ergo-Tech понимается формирование замыкающей части крепежа путем вращения сердечника, завершающееся обрывом технологического хвостовика.

После выполнения соединений с использованием заклепок высокого сопротивления срезу Ergo-tech контролировались следующие параметры:

- высота и диаметр замыкающего элемента крепежа (рис. 8);

- отсутствие трещин и сколов на замыкающем элементе крепежа.

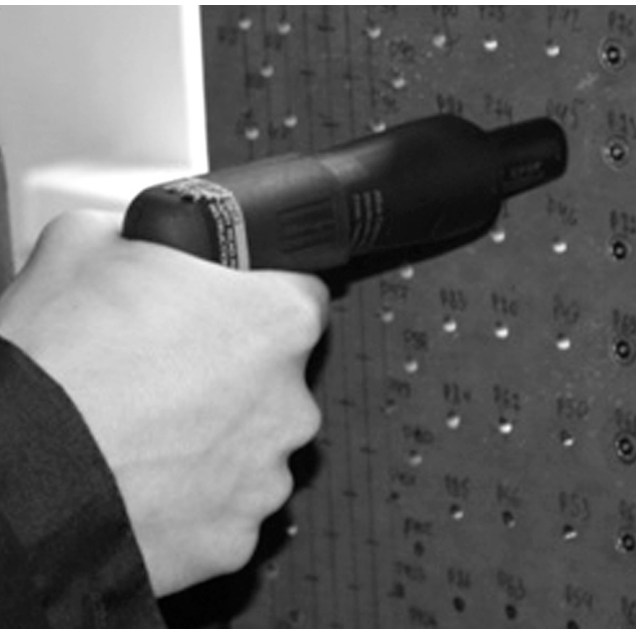

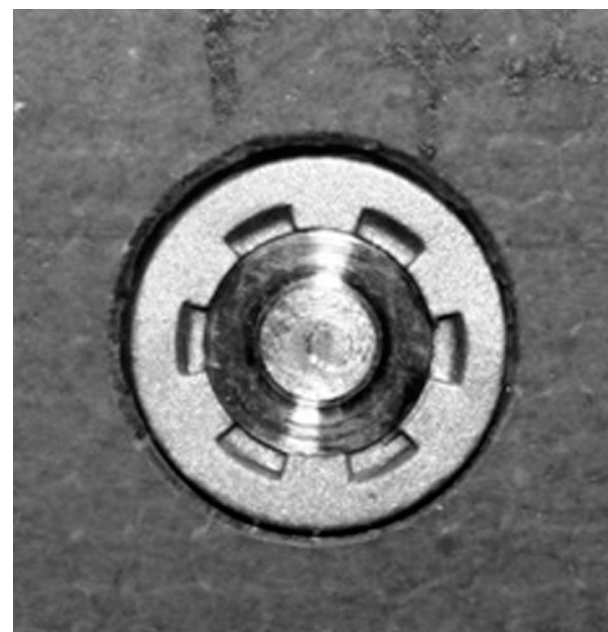

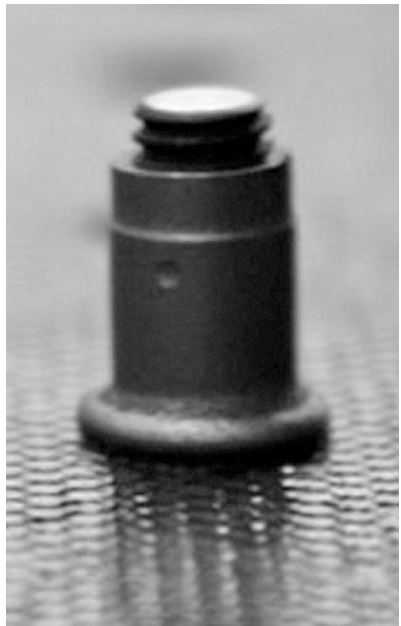

Рис. 7. Постановка заклепок высокого сопротивления срезу Ergo-tech:

а) - образование замыкающего элемента; б) - закладная головка установленного крепежа; в) - замыкающий элемент установленного крепежа

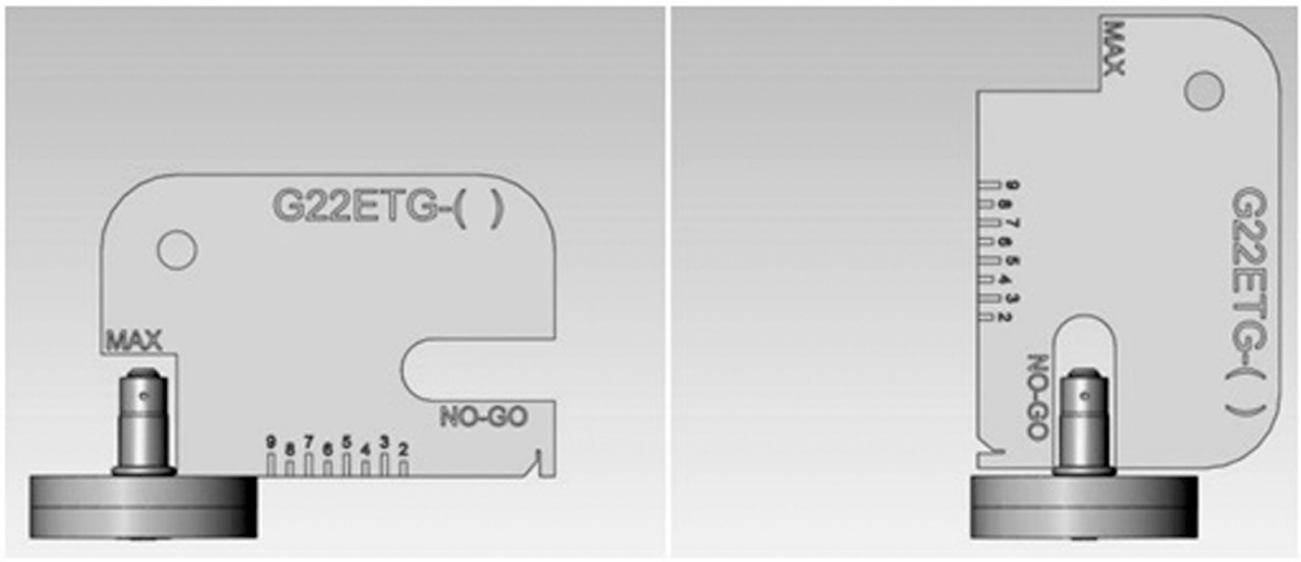

Рис. 8. Контролируемые параметры замыкающего элемента Ergo-tech 


\section{Результаты}

Результаты контроля не выявили отклонений измеренных параметров от их значений, указанных в технической документации производителя на крепеж Ergo-tech, что является свидетельством высокого уровня стабильности качества соединений. При этом, следует отметить, что качество соединений, выполненных с использованием крепежа Ergo-tech, в основном, обеспечивается его конструкцией и, практически, не зависит от квалификации оператора. Это оправдывает применение данного типа крепежа в зонах конструкции агрегатов планера с ограниченным доступом опе-

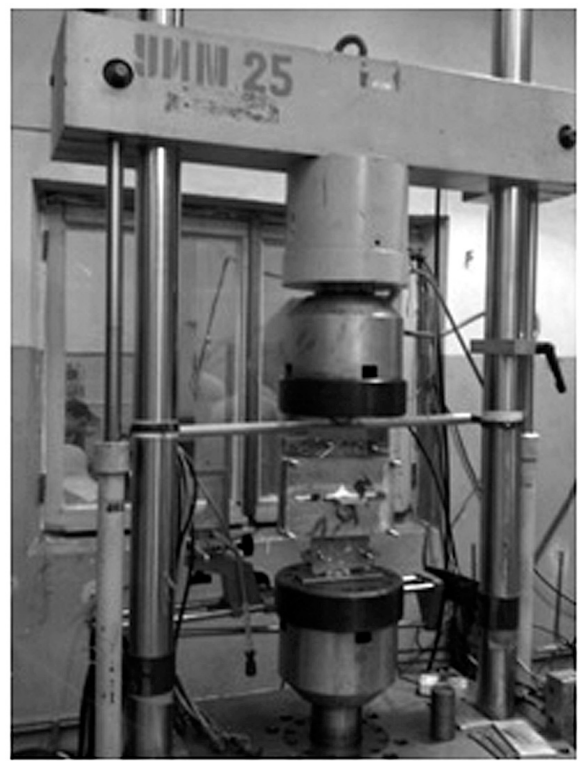

a

Рис. 10. Усталостные испытания образцов соединений: а) - испытательная машина; б) - сравнительные результаты усталостных испытаний

в) - типовой характер разрушения образцов

ратора для выполнения и контроля качества крепежных точек.

Усталостные испытания проводились на клеемеханических образцах соединений, имитирующих поперечные стыки фюзеляжа. Конструкция образцов соединений, выполненных с использованием крепежа Ergo-tech с потайной головкой, представлена на рис. 9.

Испытания проводились при асимметричном цикле нагружения с приложением растягивающих нагрузок. Типовым характером разрушения образцов было разрушение пластины в сечении по кромке перестыковочной ленты. Прочностные параметры соединений (рис. 10), выполненных с применением крепежа Ergo-Tech, соответствуют показате-

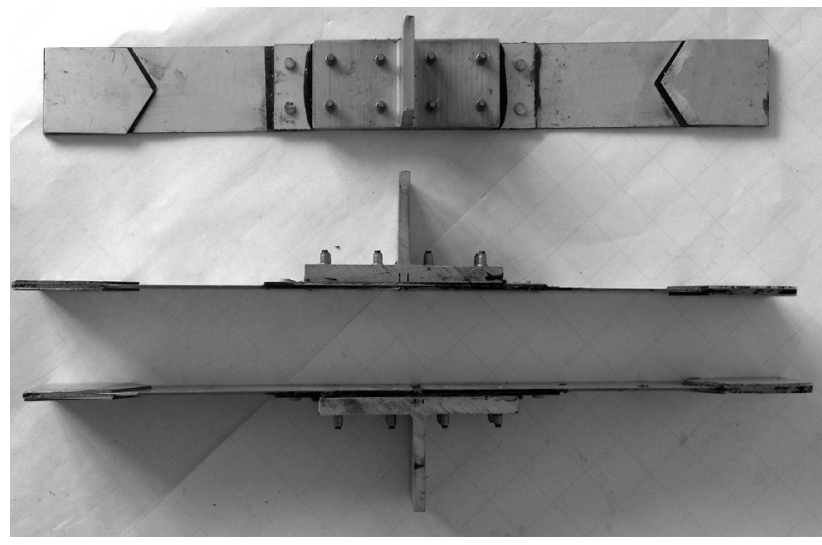

Рис. 9. Конструкция образцов соединений для усталостных испытаний

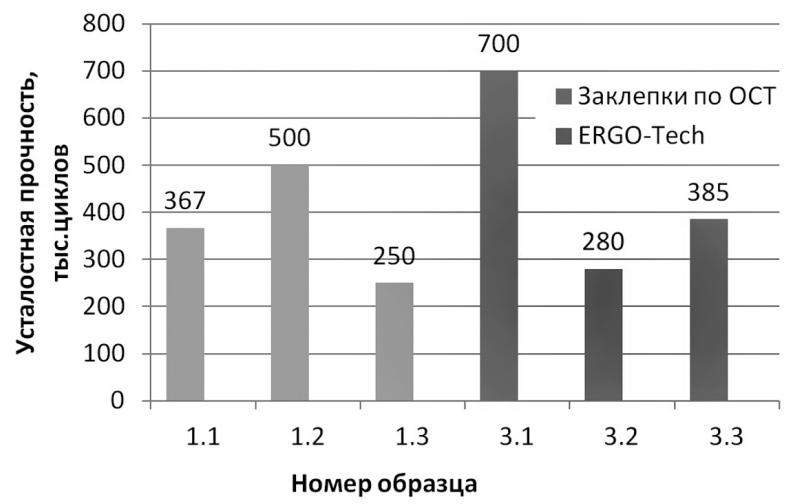

б

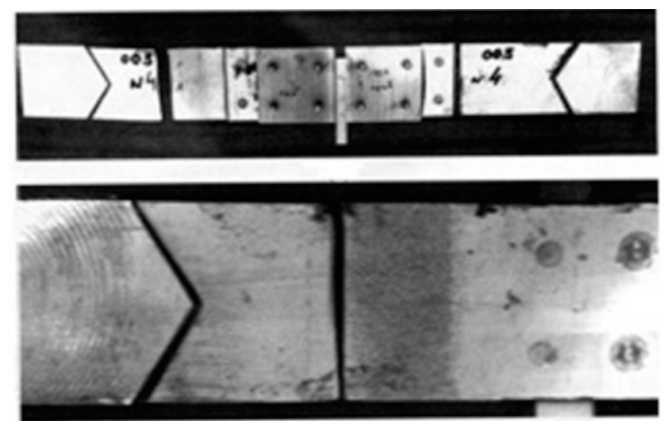

лям соединений, выполненных с применением базового крепежа по отраслевым стандартам.

Аналогичные работы планируется провести относительно других типов крепежа, представленных на рис. 4.

Результаты апробации альтернативных крепежных систем станут частью нормативного базиса, как это предусмотрено Авиационными правилами Украины, при освоении новых технологических процессов на авиационных предприятиях.

\section{Аббревиатуры}

AFSR - Alcoa Fastening System \& Rings PCC - Precision Castparts Corp. 


\section{Литература}

[1] Бычков С.А., Матвиенко В.А, Романович Г.Н. Исследование и разработка новых технологий агрегатно-сборочного производства гражданских самолетов // Технологические системы. - № 1 (62). 2013. - C. 71-78. - ISSN 2074-0603. http://technologicalsystems.com.ua/images/journal/2013/files/ts62.pdf

[2] Матвиенко В.А., Рудько А.Н., Братухин В.А. Крепежные системы для соединений элементов конструкций планера самолетов нового поколения // Технологические системы. - № 5 (49). - 2009. C. 107-111. - ISSN 2074-0603. http://technologicalsystems.com.ua/images/journal/2009/files/ts49.pdf

[3] Boeing: The fight for fasteners/ William Davidson Institute at the University of Michigan/ Tauber insti- tute for global operations, case 1-428-787, November 17,2009

[4] Lunsford, Lynn and Paul Glader. Boeing's Nuts-andBolts Problem./ The Wall Street Journal, 19 June, 2007.

[5] Lengthy wait for aircraft is over./ BBC News, 13 Oct. 2007.

[6] Официальный сайт кампании Alcoa Fastening Systems \& Rings Aerospace / https://www.alcoa.com/ fastening_systems_and_rings/aerospace/en/info_page/ home.asp

[7] Christopher S. Tang and Joshua D. Zimmerman. Managing New Product Development and Supply Chain Risks: The Boeing 787 Case./ Supply Chain Forum. - Vol. 10, N²,2009. - p. 74-86.

Matviienko V.A. ${ }^{1}$, Dveirin A. Z. ${ }^{2}$, Vasylevskyi E. T. ${ }^{2}$, Romanovich G. N. ${ }^{2}$, Rudko A. N. ${ }^{1}$

${ }^{1}$ Ukrainian Research Institute of Aviation Technology, JSC. Ukraine, Kiev

${ }^{2}$ ANTONOV, State-owned Enterprise. Ukraine, Kiev

\section{FASTENING SYSTEMS FOR MODERN AIRCRAFT ASSEMBLING}

The results of the analysis of the world market of fastening systems for aviation structures are briefly presented, the main manufacturers are listed, and the basic tendencies of development of the market are allocated. The analysis of the existing normative basis of fastening systems used by Ukrainian aircraft manufacturing enterprises is performed. Alternative variants of fastening systems are offered, the basic stages of their approbation are described, and also separate results are presented. [dx.doi.org/10.29010/081.9]

Keywords: joints; fastening systems; blind bolts; Erho-Tech; approbation.

\section{References}

[1] Bychkov S.A., Matvienko V.A, Romanovich G.N. Research and development of new technologies of civil aircraft aggregate-assembly production // Technological Systems. - \# 1 (62). - 2013. - P. 71-78. - ISSN 2074-0603. (In Russian) http://technological-systems.com.ua/images/journal/2013/files/ts62.pdf

[2] Matvienko V.A., Rud'ko A.N., Bratuhin V.A. Krepezhnye sistemy dlja soedinenij jelementov konstrukcij planera samoletov novogo pokolenija./ Tehnologicheskie sistemy, №5(49), 2009, str.107-111. (In Russian) http://technologicalsystems.com.ua/images/journal/2009/files/ts49.pdf

[3] Boeing: The fight for fasteners/ William Davidson Institute at the University of Michigan/ Tauber institute for global operations, case 1-428-787, November 17,2009.

[4] Lunsford, Lynn and Paul Glader. Boeing's Nuts-and-Bolts Problem./ The Wall Street Journal, 19 June, 2007.

[5] Lengthy wait for aircraft is over./ BBC News, 13 Oct. 2007.

[6] WEB Alcoa Fastening Systems \& Rings Aerospace / https://www.alcoa.com/fastening_systems_and_rings/ aerospace/en/info_page/home.asp

[7] Christopher S. Tang and Joshua D. Zimmerman. Managing New Product Development and Supply Chain Risks: The Boeing 787 Case./ Supply Chain Forum.-Vol. 10, №2,2009. - p.74-86. 